\title{
VARIABILIDADE SEMÂNTICA E SINTÁTICA DOS NOMES DOS DIAS DA SEMANA
}

\author{
IVA SVOBODOVÁ \\ Universidade de Masaryk, Brno
}

\section{SEMANTIC AND SYNTACTIC VARIABILITY OF THE NAMES OF THE DAYS OF THE WEEK}

This study represents the summary of a wider qualitative and quantitative investigation and contains significant results pertaining to the nominal and adverbial constructions which incorporate the names of the days of the week in contemporary Portuguese. We focus on the internal structure of constructions introduced by different prepositions and study their temporal and aspectual value. One of the most important aspects of our investigation is also the occurrence of definite, and marginally also indefinite articles with the names of the days of the week in different constructions, and the position of the adjectives próximo/ passado in these expressions. We likewise include liturgical names and proverbs. Our aim is also to prove that the occurrences of the article depend on the prepositional type. For our investigation, we used the corpora of Linguateca (Cetem Público and Vercial), InterCorp and Corpus do Português.

Keywords: article; preposition; names of the days of the week; aspect; time

Palavras-chave: artigo; preposição; nomes dos dias da semana; aspeto; tempo

\section{Introdução}

O presente trabalho tem por objetivo apontar caminhos para possíveis análises dos diferentes comportamentos de expressões adverbiais de tempo quando estas se encontram em sintagmas preposicionados em que o núcleo sintático introduz o nome dos dias da semana. A referência temporal destas expressões adverbiais é submetida, maioritariamente, ao subsistema verbal português, prendendo-se, muitas vezes, com os valores temporal e aspetual.

O propósito da nossa pesquisa será, concomitantemente, analisar a estrutura interna destas expressões, limitando-nos às suas ocorrências em português europeu. Dividiremos o nosso trabalho em duas partes principais. A primeira parte abordará o problema 
dos sintagmas preposicionados com os núcleos "em" e "a” do ponto de vista temporal e aspetual, sendo a segunda parte dedicada à análise da ocorrência do artigo em outros sintagmas preposicionados.

\section{Enquadramento metodológico}

No presente estudo foram aplicados os princípios da metodologia qualitativa e quantitativa. Na primeira parte, dedicada ao estudo qualitativo das possíveis interpretações aspetuais e temporais das construções encontradas, partimos de "Nova Gramática do Português Contemporâneo" (Cunha e Cintra 1999), "Moderna Gramática Portuguesa” (Bechara 2000), “Gramática de Uso” (Neves 2001), "Gramática da Língua Portuguesa” (Mateus, Brito, Duarte, Hub: 1989 e 2003), entre outros. ${ }^{1}$ Para conseguirmos obter o maior número de exemplos, recorremos aos corpora Linguateca, Corpus do Português, InterCorp e também ao "Dicionário da Língua Portuguesa Contemporânea" (Casteleiro et al. 2001). Tal como sinaliza o título do nosso texto, todas as construções encontradas foram analisadas do ponto de vista sintático (observando-se a estrutura interna dos sintagmas preposicionados e não preposicionados) e semântico (analisando-se os valores temporal e aspetual das diferentes construções). A segunda parte do trabalho, dedicada à pesquisa da ocorrência do artigo nos sintagmas preposicionados, consistiu, pelo contrário, num estudo quantitativo da ocorrência do artigo nestas expressões e da posição do modificador próximo e passado no sintagma.

De referir que, ao contrário de outras análises da nossa autoria (p. ex. Svobodová $2009,2010)^{2}$, na presente pesquisa partimos dos valores constantes do artigo, sendo que -segundo as nossas observações-, no caso dos dias da semana, o artigo apresenta, em cada construção prototípica, um valor estável, tendo em diferentes registos (oral e falado) um uso consagrado e constante.

Para ilustrar a variabilidade sintagmática das expressões em questão, mencionamos, nos seguintes esquemas, nove estruturas concretas a serem tipificadas nas seguintes secções do nosso trabalho, de acordo com os valores temporal e aspetual e com a função sintática.

- $\quad[$ Prep + Det $+\mathrm{N}]$

- $\quad[$ Prep + Det $+\mathrm{N}+$ Adj $]$

- $\quad[$ Prep + Det + Adj $+\mathrm{N}]$

- $[\mathrm{N}+$ Prep $+\mathrm{N}+\mathrm{Adj}]$

- $[$ Prep $+\mathrm{N}]$

- $[\mathrm{N}]$

- $[\mathrm{N}+\mathrm{Adj}]$

- $[$ Det $+\mathrm{N}]$

- $\quad[$ Det + Adj $+\mathrm{N}]$ na(s) segunda(s)-feira(s)/à(s) segunda(s)-feira(s)

na segunda-feira passada

na próxima segunda-feira

noite de segunda-feira próxima/passada

de/paralem segunda-feira

segunda-feira

segunda-feira próxima/passada

a segunda-feira

a próxima/passada segunda-feira

1 Por ter sido realizada em junho de 2013, i. e., antes da publicação de "Gramática do Português" (Raposo E. P. 2013), a nossa pesquisa já não inclui a recente gramática nas referências bibliográficas. Apesar deste facto, ao ser consultada posteriormente, chegou-se à conclusão de que não aumentaria a parte material da pesquisa.

2 A nossa pesquisa completa encontra-se no link: https://is.muni.cz/www/9255/articles. 
Destaque-se que o número elevado dos sintagmas encontrados deveria implicar uma maior univocidade semântica. Adiantamos, contudo, que em alguns casos deparamos com o problema de ambiguidade, quando a mesma construção ganha diferentes valores aspetuais de acordo com o texto que orbita em torno dela como mostram os seguintes casos:

Terça(-feira) é o meu dia de ir a Brno. (aspeto durativo: frequentativo/iterativo) Terça(-feira) fui a Brno. (aspeto pontual: evento)

A variabilidade das referências temporais e aspetuais, como já foi adiantado, é muitas vezes deduzível a partir do contexto. As formas isoladas, não obstante, levaram-nos a colocar as seguintes questões:

- Como é que as formas concretas dos sintagmas se relacionam com a categoria verbal de tempo e aspeto?

- Existem diferenças relativas à frequência de uso de construções sinonímicas como são, por exemplo, todos os sábados/nos sábados/aos sábados/ao sábado?

- De que fator depende a ocorrência do artigo nos sintagmas preposicionados (no sábado $\times$ de sábado)?

- Qual é a influência do núcleo preposicional na flutuação do modificador?

- Qual é a posição dos modificadores dentro das construções e de que fatores depende a sua flutuação?

- Qual é a influência do modificador na ocorrência do artigo?

\section{Aspeto e tempo verbais}

Ora, o tempo e o aspeto são dois fatores decisivos que predeterminam a seleção concreta da expressão adverbial. Quanto ao tempo, é necessário ter presente que este pode ser de natureza linguística e ontológica. Enquanto que o tempo linguístico apresenta uma categoria gramatical cujo repertório pode variar de língua para língua, o tempo ontológico parte do conhecimento geral, a sua perceção é universal, apresentando um eixo temporal difuso, iniciado e terminado num ponto infinito. No meio encontra-se o ponto mais importante, o momento da enunciação, que divide o eixo temporal em três partes: presente, passado e futuro. Nas línguas checa e portuguesa, estes três tempos básicos são deíticos/absolutos. Contudo, nas línguas românicas, além destes, existem ainda tempos gramaticais relativos, os quais veiculam a informação sobre a relação entre o momento de enunciação e os tempos paralelos, anteriores ou posteriores. Consequentemente, existe uma considerável diferença entre o sistema verbal português, que possui um paradigma muito mais rico em tempos, e o sistema verbal checo, que carece de tempos relativos mas que, para exprimir as relações temporais secundárias, recorre a outros meios morfológicos ou lexicais.

No que ao aspeto diz respeito, "a estrutura interna subatómica” (Parsons 1991 in Mateus, Brito, Duarte, Hub et al. 2003: 129) dos casos por nós estudados pode ser vista, em princípio, a partir de três ângulos. 
1. Levando em consideração a tipologia aspetual baseada na distinção entre eventos, estados, processos culminados, culminações e pontos, a mesma construção pode ser utilizada, indiferentemente, com todos os tipos aspetuais do verbo que implicam singularidade de ação, sendo as outras propriedades (a homogeneidade, a dinamicidade, a duração, o estado consequente e a telicidade) ${ }^{3}$ irrelevantes para a seleção de uma ou outra construção. Veja-se os seguintes exemplos onde a mesma construção ocorre na frase independentemente da natureza aspetual da proposição: ${ }^{4}$
A Maria estava triste no domingo.
(estado)
Choveu no sábado passado.
(processo)
O João deu o quadro ao filho na segunda-feira.
Na terça-feira o Pedro chegou tarde ao emprego.
(processo culminado)
O público suspirou de alívio na quarta-feira.
(culminação)
(processo)

2. O segundo passo consistiu em analisar os valores aspetuais pontuais, que descrevem eventos cuja duração é a "do momento ou tempo de curta duração em que ocorre a mudança de estado ou transição sofrida por uma dada entidade" (Mateus, Brito, Duarte, Hub 1989: 90). Supomos que todos os predicadores que apresentem os valores pontuais, ou seja, tanto os valores incoativo, causativo, incetivo como os valores conclusivo e cessativo ${ }^{5}$ podem ser localizados num determinado dia. Este ponto de vista, em termos de variabilidade estrutural, mostrou que o repertório dos adverbiais que exprimem a duração dos eventos num determinado dia, é completamente submetido às referências temporais distribuídas no eixo temporal como mostram os seguintes exemplos:

$\begin{array}{ll}\text { O padre terá morrido na sexta-feira passada. } & \text { (incoativo) } \\ \text { A Maria abriu o envelope no sábado passado. } & \text { (resultativo) } \\ \text { Domingo, começou a chover. } & \text { (incetivo) } \\ \text { Chegarão na próxima segunda-feira. } & \text { (conclusivo) } \\ \text { Deixarei de fumar na terça-feira. } & \text { (cessativo) }\end{array}$

3. O terceiro ponto de vista permitiu-nos desenvolver uma análise mais detalhada das construções que localizam os predicadores num subintervalo diário e que apresentam o valor aspetual durativo (Mateus, Brito, Duarte, Hub 1989: 97). A seleção da construção, neste caso, representa a única situação em que a influência primária é exercida pelo aspeto, mais precisamente pela dicotomia singularidade versus pluralidade da ocorrência da proposição, e não pela referência temporal. Esta, contudo, pode ser percebida como um fator secundário que, juntamente com o contexto, perfaz a natureza aspetual geral da frase. É de referir que a distinção entre a ocorrência singular e as ocorrências plurais do referido processo ou evento reflete-se, também, na seleção do tempo verbal,

3 Mateus, Brito, Duarte, Hub et al. (2003: 137).

4 Os exemplos foram tirados da "Gramática da Língua Portuguesa" (2003: 193-203) e neles foram modificadas as expressões adverbiais de acordo com as nossas necessidades. Não incluimos nos exemplos o tempo futuro do presente, que é aspetualmente irrelevante.

5 Relembre-se que o termo Aktionsart, muitas vezes é usado nas línguas românicas noutro sentido, diferente do sentido original. 
por exemplo, de pretérito perfeito versus imperfeito ou pretérito perfeito composto. No que à análise do valor durativo diz respeito, os valores iterativo, frequentativo, habitual e gnómico dos estados e processos apresentam as suas especificidades relativamente à escolha da construção adverbial. Por exemplo, nas frases:

O João trabalha à sexta-feira. / O João trabalha na sexta-feira.

“Trabalhar à sexta-feira” apresenta um valor aspetual habitual, iterativo ou frequentativo, enquanto que no segundo exemplo, o predicado "trabalhar na sexta-feira" aponta para o carácter singular do processo. Consequentemente, não seriam aceitáveis frases como:

${ }^{\star}$ O João normalmente trabalha na sexta-feira.

Partindo das classes e formas aspetuais típicas das línguas portuguesa e checa, verificou-se uma diferença essencial na localização de um evento/estado/processo num determinado dia, entre a língua checa e a língua portuguesa. Enquanto que, em checo, a oposição aspetual se exprime, primariamente, pelo processo gramatical que consiste na seleção de uma concreta forma aspetual do verbo, em português isto é feito por meio da expressão adverbial. Comparem-se as expressões em negrito, aspetualmente relevantes nas duas línguas, ilustradas no seguinte quadro:

\begin{tabular}{|l|l|l|}
\hline & expressão adverbial & tempo verbal \\
\hline Português & $\begin{array}{l}\text { À(s) segunda(s)-feira(s) - iteratividade } \\
\text { Na segunda-feira-pontualidade }\end{array}$ & vou a Lisboa. \\
\hline Checo & Vpondělí & $\begin{array}{l}\text { (po)jedu do Lisabonu. - pontualidade } \\
\text { jezdím do Lisabonu. - iteratividade }\end{array}$ \\
\hline
\end{tabular}

\subsection{Análise temporal}

Aplicando o método de distribuição temporal, ${ }^{6}$ como já foi adiantado, no eixo temporal consideraram-se indispensáveis cinco referências temporais, como se pode ver no seguinte esquema:

Ia $\mathrm{Ie}$

Ie $\quad$ Ip

$\begin{array}{ccccc}\mathrm{Ij} & \mathrm{Ik} & & \mathrm{Ipi} & \mathrm{Ip} \\ 1 & 2 & 3 & 4 & 5\end{array}$

6 A distribuição temporal e os símbolos utilizados no presente trabalho estão convencionalmente formularizados em Mateus, Brito, Duarte, Hub et al. (1989: 78-79).

$\mathbf{I j}=$ pretérito mais-que perfeito; $\mathbf{I} \mathbf{k}=$ pretérito perfeito; $\mathbf{I e}=$ presente; $\mathbf{I} \mathbf{p}=$ futuro; $\mathbf{I p i}=$ futuro iminente. 
Partindo da tipologia pontualidade $\times$ durabilidade (Mateus, Brito, Duarte, Hub et al. 1989: 90), incluímos, na análise temporal todos os valores aspetuais pontuais, i.e. incoativo, causativo, incetivo, conclusivo e cessativo (Mateus, Brito, Duarte, Hub et al. 1989: 90)7 caracterizados como enunciados que descrevem "eventos cuja duração é a do momento ou tempo de curta duração em que ocorre a mudança de estado ou transição sofrida por uma dada entidade" (Idem. Ibidem). As premissas a que chegámos, como veremos, poderão ser aplicadas, também, a dois valores aspetuais durativos: o permansivo e o cursivo.

Proceda-se à análise dos sintagmas preposicionais em torno de cujo núcleo orbitam os nomes em questão.

\subsubsection{O futuro Ip}

O tempo futuro, no nosso caso, exprimirá duas fases de posterioridade do intervalo de tempo que contém o estado das coisas descrito relativamente ao momento de enunciação: a fase iminente e a fase não iminente, distanciada do momento presente. Como o tempo é um fenómeno que, por um lado representa uma grandeza física exatamente mensurável, mas, por outro lado, é muito relativo e submetido à perceção individual do falante, a divisão do futuro nestas duas fases de posterioridade também dependerá da atitude subjetiva dos interlocutores acerca da referência temporal da proposição. Como veremos, esta terá uma influência essencial na seleção da construção. Refira-se que nesta parte só foram analisados os sintagmas preposicionados que têm o núcleo em, sendo outros núcleos preposicionais tratados nesta secção apenas marginalmente e desenvolvidas na secção 4 .

A construção típica que localiza o evento no Ip, ou seja, num intervalo posterior ao momento de enunciação, afastado deste, é o sintagma preposicionado SP $=$ [Prep + Det $+\mathrm{Adj}+\mathrm{N}$ ] com o adjetivo modificador próximo que se encontra, tipicamente, em posição pré-nominal. Às vezes, quando dado contextualmente, o modificador "próximo" é omitido, sendo resultado o sintagma preposicionado SP $=[$ Prep + Det $+\mathrm{N}]$.

Ie Ipi Ip

Vai chegar na quarta-feira.

Na próxima terça(-feira) haverá um desfile.
$[$ Prep + Det $+\mathrm{N}]$

$[$ Prep + Det + Adj $+N]$

7 No nosso trabalho, não pretendemos analisar as diferenças existentes entre os conceitos Aspeto e Aktionsart. O termo Aspeto, em nossa pesquisa, será aplicado tanto aos tipos como às formas aspetuais, partindo da definição geral do Aspeto de Mateus, Brito, Duarte, Hub (1989: 90) descrito como "a categoria que exprime o modo de ser (interno) de um estado de coisas descrito através de expressões de uma língua natural, por seleção de um predicador pertencente a uma dada classe, por quantificação do intervalo de tempo em que o estado de coisas descrito está localizado e/ou por referência à fronteira inicial ou final desse intervalo ou a intervalos adjacentes". 
No caso de registos que apresentam um maior grau de formalidade como são, por exemplo, notícias e textos jornalísticos, convites e avisos oficiais etc., foram verificadas ocorrências de sintagmas reduzidos, não preposicionados (geralmente na função apositiva) como ilustra o seguinte caso:

Ie Ipi Ip

A próxima reunião plenária terá lugar no dia 19 de março, quarta-feira, pelas 15 horas. $^{8}$

$$
S N=[\mathrm{N}]-\text { função apositiva }
$$

Além destas três construções, verificou-se, a ocorrência ocasional de mais três sintagmas: $[\operatorname{Adj}+\mathrm{N}],[\mathrm{N}+\operatorname{Adj}]$ e $[$ Prep + Det + N + Adj]. O seu número muito baixo, contudo, sinaliza, evidentemente, um uso pouco habitual e periférico. Entre outros, encontrámos os seguintes exemplos:

... a argumentação deve ser apresentada até 9 de Setembro, próxima sexta-feira. ${ }^{9}$

$[$ Adj $+\mathrm{N}]$

O FC Porto jogará ... quarta-feira próxima... ${ }^{10}$

$[\mathrm{N}+$ Adj]

Após, na quarta-feira próxima, ser produzida a acusação definitiva... ${ }^{11}$

$[$ Prep + Det + Adj $+\mathrm{N}]$

O problema da flutuação do modificador próximo ${ }^{12}$ mostrou-se ser um dos pontos cruciais nesta parte da pesquisa. De facto, verificou-se que a posição de próximo se depreende da estrutura interna do sintagma: por um lado, observou-se a colocação preferencial pré-nominal de próximo no sintagma preposicionado SP $=[$ Prep + Det + $\operatorname{Adj}+\mathrm{N}$ ] e no sintagma não preposicionado na função circunstancial [N + Adj], por outro lado, na função de sujeito, predominou a posição pós-nominal [Det + N + Adj]. Comparem-se os seguintes quadros de dados: ${ }^{13}$

8 Costa, Santos \& Cardoso (2008), http://linguateca.pt/CETEMPublico.

9 Idem.

10 Idem.

11 Idem.

12 De acordo com Hricsina, o adjetivo próximo/passado deveria pertencer aos adjetivos quantitativos, que "não servem propriamente para qualificar os substantivos, mas a sua função está geralmente ligada à noção de quantificação ou intensidade (principal, mero, pleno, simples, raro, certo). Não aparecem em posição predicativa" (Hricsina 2013: 205). De acordo com F. Oliveira, este tipo de adjetivos deveria pertencer aos adjetivos modificadores do significado ou intensão dos nomes (Mateus, Brito, Duarte, Hub 2003: 377). Nós utilizaremos, ao longo do nosso trabalho, apenas a designação modificador.

13 Os dados predominantes nos quadros são marcados em negrito e exemplificados. 
Sintagma preposicionado (na próxima $\mathrm{x}$-feira versus na $\mathrm{x}$-feira próxima)

\begin{tabular}{|c|c|c|c|}
\hline \multirow[b]{3}{*}{$\mathrm{x}$} & & \multicolumn{2}{|c|}{ número das ocorrências encontradas } \\
\hline & & {$[$ Prep + Det + Sadj + N] } & {$[$ Prep + Det + N + SAdj $]$} \\
\hline & & na próxima $x$-feira & na x-feira próxima \\
\hline $2^{\mathrm{a}_{-}}$ & \multirow{5}{*}{ feira } & 1482 & 6 \\
\hline $3^{a_{-}}$ & & 953 & 3 \\
\hline $4^{a_{-}}$ & & 801 & 5 \\
\hline $5^{a_{-}}$ & & 752 & 2 \\
\hline $6^{\mathrm{a}_{-}}$ & & 752 & 2 \\
\hline sábado & & 862 & 1 \\
\hline domingo & & 860 & 2 \\
\hline
\end{tabular}

Exemplos da colocação pré-nominal:

As duas equipas voltam a encontrar-se no próximo sábado. ${ }^{14}$ Li Peng chega a Lisboa no próximo domingo. ${ }^{15}$

Sintagma não preposicionado (, próxima x-feira, versus, x-feira próxima,)

\begin{tabular}{|c|c|c|c|}
\hline \multirow[b]{3}{*}{$\mathrm{x}$} & & \multicolumn{2}{|c|}{ número das ocorrências encontradas } \\
\hline & &,$[\operatorname{Adj}+\mathrm{N}]$ & ,[N + Adj] \\
\hline & & , próxima x-feira, & , $x$-feira próxima, \\
\hline $2^{\mathrm{a}_{-}}$ & \multirow{5}{*}{ feira } & 0 & 4 \\
\hline $3^{a_{-}}$ & & 0 & 4 \\
\hline $4^{\mathrm{a}_{-}}$ & & 1 & 16 \\
\hline $5^{\mathrm{a}_{-}}$ & & 0 & 1 \\
\hline $6^{a_{-}}$ & & 1 & 1 \\
\hline sábado & & 0 & 6 \\
\hline domingo & & 0 & 11 \\
\hline
\end{tabular}

Exemplos da colocação pós-nominal:

No Porto, o concerto está marcado para o Coliseu, terça-feira próxima. ${ }^{16}$ O próximo encontro do Milan, domingo próximo, em Génova, será decisivo. ${ }^{17}$

14 Idem.

15 Idem.

16 Idem.

17 Idem. 
Sintagma não preposicionado (A próxima x-feira, versus A x-feira próxima) ${ }^{18}$

\begin{tabular}{|c|c|c|c|}
\hline \multirow[b]{3}{*}{$\mathrm{x}$} & & \multicolumn{2}{|c|}{ número das ocorrências encontradas } \\
\hline & & {$[\operatorname{Det}+\operatorname{Adj}+\mathrm{N}]$} & {$[$ Det $+N+$ Adj $]$} \\
\hline & & A próxima $x$-feira, & A x-feira próxima \\
\hline $2^{a_{-}}$ & \multirow{5}{*}{ feira } & 1 & 0 \\
\hline $3^{a_{-}}$ & & 3 & 1 \\
\hline $4^{\mathrm{a}_{-}}$ & & 1 & 0 \\
\hline $5^{\mathrm{a}_{-}}$ & & 2 & 0 \\
\hline $6^{a_{-}}$ & & 1 & 0 \\
\hline sábado & & 1 & 1 \\
\hline domingo & & $\mathbf{0}$ & 0 \\
\hline
\end{tabular}

Exemplos da colocação pré-nominal:

A próxima quarta-feira, será um dia simbólico para a astronomia europeia. ${ }^{19}$ A próxima sexta-feira é o dia das mentiras. ${ }^{20}$

Enquanto que nos casos anteriores a colocação de próximo se verificou ser levemente flutuante, curiosamente, quando o sintagma preposicionado foi introduzido por um outro núcleo preposicional como, por exemplo, para, a única colocação encontrada durante a pesquisa no corpus CetemPúblico foi, também, a pré-nominal.

Sintagma preposicionado (para a próxima $\mathrm{x}$-feira versus para a $\mathrm{x}$-feira próxima)

\begin{tabular}{|c|c|c|c|}
\hline & & \multicolumn{2}{|c|}{ número das ocorrências encontradas } \\
\hline & & {$[$ Prep + Det + Adj + N $]$} & {$[$ Prep + Det + N + Adj $]$} \\
\hline $\mathrm{x}$ & & para a próxima $x$-feira & para a x-feira próxima \\
\hline $2^{a_{-}}$ & \multirow{5}{*}{ feira } & 236 & 0 \\
\hline $3^{a_{-}}$ & & 170 & 0 \\
\hline $4^{a_{-}}$ & & 166 & 0 \\
\hline $5^{a_{-}}$ & & 136 & 0 \\
\hline $6^{a_{-}}$ & & 163 & 0 \\
\hline sábado & & 154 & 0 \\
\hline domingo & & 93 & 0 \\
\hline
\end{tabular}

18 Em nossa pesquisa, por razões práticas, limitámo-nos a procurar os sintagmas nominais com próximo apenas na função de sujeito, pelo que obtivemos apenas um número pouco representativo de ocorrências. Outras funções sintáticas deste sintagma foram pesquisadas apenas acidentalmente e levam-nos a supor que a posição pré-nominal é predominante em todas as outras funções do sintagma nominal que entram na valência do verbo, por exemplo. predicativa e objetiva como exemplificam as seguintes frases: As inscrições dos candidatos têm como prazo limite a próxima sexta-feira. Sobretudo após o norte-americano Robert Frowick, (...), ter fixado a próxima sexta-feira como a data limite para o afastamento de Karadzic. (exemplos do corpus CetemPúblico)

19 Idem.

20 Idem. 
Exemplo da colocação pré-nominal:

E para a próxima quinta-feira está já marcada uma greve geral. ${ }^{21}$

\subsubsection{O presente}

O tempo presente, que exprime a simultaneidade do intervalo de tempo em que ocorre o estado de coisas descrito serve, em nossa análise, apenas como o ponto de divisão entre o passado e o futuro e como o ponto, em torno do qual orbita o espaço iminente descrito mais abaixo. Normalmente, o presente utilizado com os nomes dos dias da semana na forma do sintagma nominal reduzido [N] representa o valor aspetual durativo, cursivo ou permansivo e, habitualmente, é especificado ainda pelo advérbio hoje, p. ex.: "Hoje é segunda-feira.", ou "Hoje, segunda-feira, vamos falar das tradições de Natal." Apesar de ter um ponto inicial e um outro final, relativamente ao momento de enunciação, o dia é visto como um intervalo de tempo que ainda está em curso, sendo a proposição considerada como atélica.

Ie

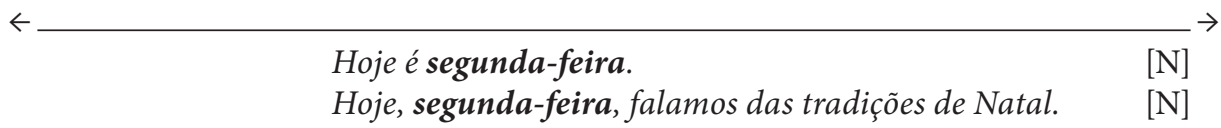

\subsubsection{O futuro Ipi e o passado Ik iminentes}

A razão que nos levou a incluir estes dois tempos na mesma secção foi a analogia de iminência do evento projetada tanto no passado, como no futuro. $\mathrm{O}$ facto de no momento de enunciação o interlocutor preferir, subjetivamente, exprimir a iminência do estado de coisas descrito, torna-se o fator decisivo que leva, às vezes, ao uso do sintagma não preposicionado (adverbial) em vez do preposicionado e, também, como veremos mais adiante, predeterminará a seleção dos tempos verbais. ${ }^{22}$ Destaque-se que não se admite, neste caso, o uso do modificador próximo e passado, pertencendo estes apenas aos pontos 3.1.1 e 3.1.5.

Ik Ie Ipi

Terça fui ao teatro. [N]

Vai chegar quarta-feira. [N]

Se é verdade que a localização dos eventos, no seu aspeto pontual, exige uma determinada construção adverbial, poderíamos, no sentido inverso, pressupor, que também a seleção dos tempos verbais será condicionada pela construção circunstancial. Supomos

21 Idem.

22 Ao mesmo tempo, o que em todos os casos deve ser respeitado são as diferenças existentes no registo formal (+feira) e informal (-feira). 
que as frases que exemplificam os dois pontos temporais iminentes (passado e futuro), poderiam, consequentemente, resultar anómalas (se não agramaticais) ao serem usadas, por exemplo, com os tempos pretérito perfeito composto, imperfeito ou mais-que-perfeito. As nossas hipóteses não são, contudo, documentadas por um número suficiente de ocorrências para podermos categoricamente afirmar esta (in)compatibilidade. Ao mesmo tempo, estamos conscientes de que (in)compatibilidade pode ser influenciada dialetologica ou diatopicamente.

?Terça tinha ido/fora ao teatro.

?Terça ia/costumava ir ao teatro. (tinha ido/fora $=$ pretérito mais que perfeito) (ia/costumava $i r=$ pretérito imperfeito)

Deduza-se que a iminência do evento localizado pelo nome do dia da semana deveria refletir-se, logicamente, no discurso indireto de acordo com a ordenação temporal descrita, podendo ser, contudo, submetida, ao uso individual. Vejamos como se poderia transmitir, consequentemente, para o discurso relatado, o seguinte exemplo:

Discurso não relatado: O João disse: "Segunda(-feira) fui/vou ao teatro."

$\boldsymbol{\nabla} \boldsymbol{\nabla}$

Discurso relatado: O João disse que?23 segunda(-feira) ?tinha ido/?iria ao teatro.

Discurso relatado: $O$ João disse que na segunda(-feira) tinha ido/iria ao teatro.

\subsubsection{I k O passado não iminente Ij}

No caso de o passado ser colocado no eixo temporal antes do ponto não iminente $\mathrm{Ij}$, ocorre tipicamente o sintagma preposicional [Prep + Det $+\mathrm{N}+$ Adj] ou [Prep + Det + Adj $+\mathrm{N}$ ] com o modificador passado, o qual, tal como no caso de próximo, pode ocorrer em ambas as posições.

Ij

Na terça-feira passada fomos ao teatro

Na passada terça-feira fomos ao teatro
Ie

$$
\begin{aligned}
& {[\text { Prep }+ \text { Det }+N+\text { A dj }]} \\
& {[\text { Prep }+ \text { Det }+ \text { Adj }+N]}
\end{aligned}
$$

Analogamente à sua contrapartida futura, foi verificada, na função do constituinte adverbial não apositiva, uma forte predominância da sua colocação pré-nominal (às vezes dupla ou tripla comparativamente com a posição pós-nominal). Contudo, como mostra o quadro dos dados resultantes da sondagem realizada no corpus Linguateca/ CetemPúblico, também a colocação pós-nominal foi ricamente documentada por centenas de ocorrências.

${ }^{23}$ Esta construção reflete apenas as nossas hipóteses, mas como não conseguimos recolher exemplos suficientes, marcamos esta frase também por um ponto de interrogação. 
Sintagma preposicionado (na passada $\mathrm{x}$-feira versus na $\mathrm{x}$-feira passada)

\begin{tabular}{|c|c|c|c|}
\hline \multirow[b]{3}{*}{$\mathrm{x}$} & & \multicolumn{2}{|c|}{ número das ocorrências encontradas } \\
\hline & & {$[$ Prep + Det + Adj + N $]$} & {$[$ Prep + Det + N + Adj $]$} \\
\hline & & na passada $x$-feira & na x-feira passada \\
\hline $2^{a_{-}}$ & \multirow{5}{*}{ feira } & 1149 & 302 \\
\hline $3^{a_{-}}$ & & 1046 & 294 \\
\hline $4^{a_{-}}$ & & 1135 & 365 \\
\hline $5^{a_{-}}$ & & 1127 & 387 \\
\hline $6^{a_{-}}$ & & 1817 & 589 \\
\hline sábado & & 782 & 569 \\
\hline domingo & & 800 & 525 \\
\hline
\end{tabular}

Exemplo do sintagma preposicionado com o modificador na posição pré- e pósnominal:

Ainda na passada quarta-feira, o embaixador foi mesmo chamado a Washington para «consultas». ${ }^{24}$

Marc Pajot e os seus homens realizaram uma espantosa experiência na quarta-feira passada. $^{25}$

Refira-se que tal como no caso de próximo que faz parte do sintagma nominal na função de sujeito, também o modificador passado tende para a posição pré-nominal sob as mesmas circunstâncias. Os dados que o seguinte quadro ilustra são, contudo, reduzidos e servem apenas para mostrar a mesma tendência para ocupar a posição pré-nominal. ${ }^{26}$

Sintagma não preposicionado (a passada $\mathrm{x}$-feira, versus, $\mathrm{x}$-feira passada,)

\begin{tabular}{|c|c|c|c|}
\hline & & \multicolumn{2}{|c|}{ número das ocorrências encontradas } \\
\hline & & {$[$ Det + Adj + N] } & {$[$ Det + N + Adj $]$} \\
\hline $\mathrm{x}$ & & A passada $x$-feira & A x-feira passada \\
\hline $2^{a_{-}}$ & \multirow{5}{*}{ feira } & 1 & 0 \\
\hline $3^{a_{-}}$ & & 3 & 1 \\
\hline $4^{a_{-}}$ & & 1 & 0 \\
\hline $5^{a_{-}}$ & & 2 & 0 \\
\hline $6^{a_{-}}$ & & 1 & 0 \\
\hline sábado & & 1 & 1 \\
\hline domingo & & $\mathbf{0}$ & 0 \\
\hline
\end{tabular}

4 Idem.

5 Idem.

26 Na presente pesquisa, não conseguimos analisar outras funções deste sintagma a não ser a de sujeito. Ao mesmo tempo, estamos convencidas de o número não ser representativo nem depois da pesquisa de outras funções nominais, porque os nomes dos dias da semana, primariamente, exprimem uma circunstância temporal. Por isso pressupomos que os nomes dos dias da semana em construções nominais serão apenas ocasionais e pouco habituais. 
Exemplo do sintagma nominal na função de sujeito com o modificador anteposto ao nome:

A passada quinta-feira era mais um desses dias. ${ }^{27}$

A mesma tendência foi também verificada no caso de outros núcleos preposicionais, como foi, por exemplo, desde, que introduz habitualmente o nome do dia da semana com o modificador passado cuja colocação pré-nominal, ao contrário do núcleo preposicional em (no quadro anterior), verificou-se muito mais homogénea e muito menos flutuante.

Sintagma preposicionado (função circunstancial)

\begin{tabular}{|c|c|c|c|}
\hline \multirow[b]{3}{*}{$\mathrm{x}$} & & \multicolumn{2}{|c|}{ número das ocorrências encontradas } \\
\hline & & {$[$ Prep + Det + Adj + N $]$} & {$[$ Prep + Det + N + Adj $]$} \\
\hline & & desde a passada $x$-feira & desde a $\mathrm{x}$-feira passada \\
\hline $2^{a_{-}}$ & \multirow{5}{*}{ feira } & 59 & 2 \\
\hline $3^{\mathrm{a}_{-}}$ & & 45 & 2 \\
\hline $4^{\mathrm{a}_{-}}$ & & 33 & 0 \\
\hline $5^{a_{-}}$ & & 45 & 1 \\
\hline $6^{\mathrm{a}_{-}}$ & & 65 & 2 \\
\hline sábado & & 26 & 0 \\
\hline domingo & & 22 & 3 \\
\hline
\end{tabular}

Exemplo do sintagma preposicionado com o modificador anteposto ao nome:

A descida da PT tem-se consolidado desde a passada quinta-feira, nunca ultrapassando 1,5 pontos percentuais. ${ }^{28}$

Ao contrário do modificador próximo, portanto, a posição tanto pré-nominal como pós-nominal de passado foi documentada por um elevado número de ocorrências quando o sintagma preposicional foi em. Não sendo o objetivo da nossa pesquisa analisar os fatores que influenciam a flutuação do modificador, limitamo-nos, na presente pesquisa, a constatar apenas as ocorrências de ambas as posições. No entanto, pressupomos que aos fatores decisivos pertencerá (além do ritmo e da dicção da frase proferida) a construção sintática de toda a frase. Ora, como veremos no seguinte quadro, a posição do modificador dependerá da presença ou da ausência do núcleo preposicional, já que, analogamente ao modificador próximo, a situação muda completamente no caso do sintagma não preposicionado em que a ocorrência de passado na posição pós-nominal se verificou absolutamente maioritária. Veja-se o quadro que ilustra a comparação da frequência de ambas as posições no sintagma não preposicionado:

27 Costa, Santos \& Cardoso (2008), http://linguateca.pt/CETEMPublico.

28 Idem. 
Sintagma não preposicionado (, passada $\mathrm{x}$-feira versus, $\mathrm{x}$-feira passada,)

\begin{tabular}{|c|c|c|c|}
\hline \multirow[b]{3}{*}{$\mathrm{x}$} & & \multicolumn{2}{|c|}{ número das ocorrências encontradas } \\
\hline & &,$[\operatorname{Adj}+\mathrm{N}]$ &,$[\mathrm{N}+\mathbf{A d j}]$ \\
\hline & & , passada $x$-feira, & , $x$-feira passada, \\
\hline $2^{a_{-}}$ & \multirow{5}{*}{ feira } & 0 & 36 \\
\hline $3^{a_{-}}$ & & 0 & 36 \\
\hline $4^{a_{-}}$ & & 0 & 47 \\
\hline $5^{a_{-}}$ & & 0 & 62 \\
\hline $6^{a_{-}}$ & & 0 & 71 \\
\hline sábado & & 1 & 84 \\
\hline domingo & & 0 & 72 \\
\hline
\end{tabular}

Exemplo do sintagma não preposicionado apositivo na posição pós-nominal:

A maré negra provocada, quinta-feira passada, pelo naufrágio do petroleiro grego... ${ }^{29}$

De referir que para fins de reforçar a distância (o sentido da anterioridade distante), é frequente a ocorrência do demonstrativo aquele/aquela (p.ex: naquela terça-feira) e para localizar vagamente o evento no passado, é muitas vezes usada a forma um/uma, sendo que pode haver polémicas sobre se esta forma representa o artigo indefinido ou o numeral (p. ex.: numa terça-feira, uma terça-feira). ${ }^{30}$ Esta construção foi ricamente documentada no registo literário e narrativo. ${ }^{31}$

\subsection{Análise aspetual}

Como já foi referido, a variabilidade das construções adverbiais que localizam o predicador num determinado dia, depreende-se de uma escala de valores temporais. Um outro caso representam os sintagmas preposicionados que podem exprimir a pluralidade das ocorrências da predicação quando o predicador pertencer aspetualmente a um dos quatro tipos do valor durativo (Mateus, Brito, Duarte, Hub: 1989: 97): ${ }^{32}$

29 Idem.

30 Defendemos a opinião de que a forma um/uma neste caso tem a função de artigo indefinido. Partindo do facto de o numeral ser a palavra que indica os seres em termos numéricos, isto é, que atribui quantidade aos seres ou os situa em determinada sequência, seríamos levados a colocar $u m / u m a$ aos outros numerais dois/três/quatro: um domingo/dois domingos/dez domingos. Defendemos, não obstante, que esta não é a função da forma um/uma. Ao contrário, estamos convencidas de que as formas $u m / u m a$ são operadores dos processos semânticos sobre indefinidos que têm uma leitura específica.

31 Numerosos exemplos foram encontrados nos corpora InterCorp e CorpusdoPortuguês. Sendo a nossa pesquisa limitada em termos de espaço, não incluimos a exemplificação para mostrar a variabilidade das construções com os demonstrativos e indefinidos.

32 Quanto ao aspeto cursivo ou permansivo, estes relacionam-se com os eventos, com os processos e com os estados, por um lado atélicos ou inacabados, mas por outro lado também singulares, o que nos leva a aplicar o mesmo processo de seleção tal como mostrou a análise no eixo temporal: 
1. ITERATIVO:

2. FREQUENTATIVO:

3. HABITUAL:

4. GNÓMICO:
Este mês, vamos à piscina às sextas.

Aos domingos almoçamos fora.

É costume ela vir visitar-nos à terça-feira.

Talvez chore ao domingo o que ri à sexta-feira.

\subsection{1 $\mathrm{O}$ aspeto iterativo/frequentativo/habitual}

No que ao aspeto iterativo e frequentativo diz respeito, a forma verbal nem sempre veicula a informação sobre a natureza singular ou plural da situação. No caso do aspeto habitual, o reconhecimento do aspeto é feito através do verbo "costumar", o qual, intrinsecamente, aponta para a pluralidade da ação, estado ou processo. Os aspetos iterativo e frequentativo, mencionados por Mateus, Brito, Duarte, Hub et al. (1989: 89-102), podem distinguir-se apenas pela presença de uma expressão adverbial acessória, como mostra este mês na seguinte frase:

$\begin{array}{lll}\text { Este mês vou à piscina às terças. } & \text {-iterativo } & \text { [p p p p p p p p p p }]^{33} \\ \text { Às terças vou à piscina. } & \text { - frequentativo } & \leftarrow \text { p p p p p p p p p p } \rightarrow\end{array}$

Não é, contudo, objetivo do nosso trabalho demarcar as fronteiras semânticas aspetuais entre os tipos aspetuais, sendo que estes não influenciam a estrutura sintagmática. O que será essencial é a distinção entre a singularidade e a pluralidade da proposição, como ilustram os seguintes exemplos.

Terça vou ao teatro.

Terça(s) é o meu dia de ir ao teatro.
- singularidade no tempo futuro iminente

- pluralidade no tempo presente

As construções foram, outra vez, divididas segundo a sua função sintática. Considerámos essencial, portanto, tipificar as diferentes construções de acordo com se a função sintática foi de sujeito, argumento oblíquo externo (adverbial circunstancial) ou modificador (adjunto adnominal). Na função nominal de sujeito, verificaram-se duas construções possíveis: [Det $+\mathrm{N}]$ ou $[\mathrm{N}]$, sendo que para o oblíquo externo não obrigatório, a construção típica é [Prep + Det $+\mathrm{N}$ ], onde o núcleo-preposição $a$ introduz o nome do dia da semana ora no singular ora no plural. Um caso peculiar é documentado na função atributiva onde a expressão prevalecente seria o sintagma $N+[$ Prep + Det $+N]$ em que o determinante e o nome aparecem no plural. A categoria gramatical de número e a presença do artigo neste sintagma são aspetualmente relevantes, como veremos na seguinte secção em que será abordada a natureza singular das expressões $\mathrm{N}+[$ Prep + $\mathrm{N}]$ ou $\mathrm{N}+[$ Prep $+\mathrm{N}+$ Adj]: noite de sexta-feira, noite de sábado passado.

Função nominal (sujeito):

$[$ Det $+\mathrm{N}]$

$[\mathrm{N}]$
A quarta é o dia da semana em que ela tem aulas de informática. Quarta é o seu dia de ir às aulas de informática.
Nessa terça-feira a gente estava cansada. Na quarta-feira estava ainda doente. Na quinta-feira continuou a ler o livro. (tipo cursivo);

(tipo cursivo).

(tipo permansivo)

33 Os símbolos utilizados correspondem aos de Mateus, Brito, Duarte, Hub (1989: 92). 
Função adverbial (oblíquo externo):

$[$ Prep + Det $+\mathrm{N}] \quad$ Tem aulas de música à quinta-feira à tarde.

$[$ Prep + Det $+\mathrm{N}+\mathrm{N}]$ Às quintas-feiras tem aulas de música.

Função atributiva (modificadora):

$\mathrm{N}+[$ Prep + Det $+\mathrm{N}] \quad$ reunião das segundas-feiras

Um outro ponto de interesse é que para uma referência temporal existem, formalmente, diferentes construções na função adverbial aspetualmente tipologizadas como iterativas/frequentativas/habituais. Encontrámos nos corpora acessíveis e no Dicionário da Língua Portuguesa Contemporânea (2001), entre outras, as seguintes: nos sábados, todos os sábados, aos sábados, ao sábado. Verificou-se, porém, uma diferença marcante na frequência, sendo a construção menos usada "nos sábados" e "todos os sábados" e a mais usada "ao sábado" ou "aos sábados". Julgamos que esta diferença pode estar relacionada com o fator diatópico, sobretudo com as diferenças existentes entre a variedade brasileira e europeia. Não obstante, as nossas pressuposições serão desenvolvidas mais detalhadamente em estudos futuros. Os nossos primeiros resultados apontam para o facto de que a construção adverbial preposicionada introduzida pela preposição $a$ é a mais frequente, enquanto que a introduzida pela preposição em se revelou muito pouco habitual em português europeu.

\subsubsection{Aspeto gnómico}

Os nomes dos dias da semana podem veicular, igualmente, o valor aspetual gnómico, quando não existe, em rigor, localização temporal do estado das coisas descrito. Este valor aspetual ocorre, caracteristicamente, em enunciados que exprimem verdades científicas ou ideológicas e em enunciados definitórios. Esta universalidade (as verdades universais e sabedoria para todas as situações possíveis) constitui, também, a pedra-base dos provérbios. ${ }^{34}$

Neles também se mostrou útil proceder à divisão das funções sintáticas dos nomes dos dias da semana, cuja estrutura sintagmática se depreende também de se a função é nominal ou adverbial.

$\mathrm{Na}$ função adverbial de oblíquo externo não obrigatório, o sintagma preposicionado mais frequente é $[$ Prep + Det $+\mathrm{N}]$. Também foram encontrados outros dois sintagmas: [ADJ + Det $+\mathrm{N}]$ com o modificador todos - ou seja, a construção que foi considerada como pouco habitual nos corpora consultados; e o sintagma [N] em que o nome é representado por domingo. Este sintagma nominal reduzido chamou a nossa atenção, por entrar em contraste com o carácter temporalmente iminente que exprime a singulari-

34 Os provérbios portugueses e o seu sentido estão relacionados com a tradição judaico-cristã no modo como é visto o trabalho, o respeito pelos dias de descanso e o calendário religioso. A sexta-feira é normalmente relacionada com a Paixão de Cristo, sendo considerada um dia de luto, tristeza, dor, e um dia "santo", isto é de forte simbolismo e conotação religiosa (Svobodová 2012). Na tradição romana, os dias da semana que tinham " $r$ " (Marte, Mercurio e Vénus/Veneris) eram de pouca sorte $\left(3^{a}, 4^{a}\right.$ e $\left.6^{a}\right)$. 
dade de proposição no tempo futuro iminente (veja-se a secção 3.1.3). Compare-se as seguintes construções:

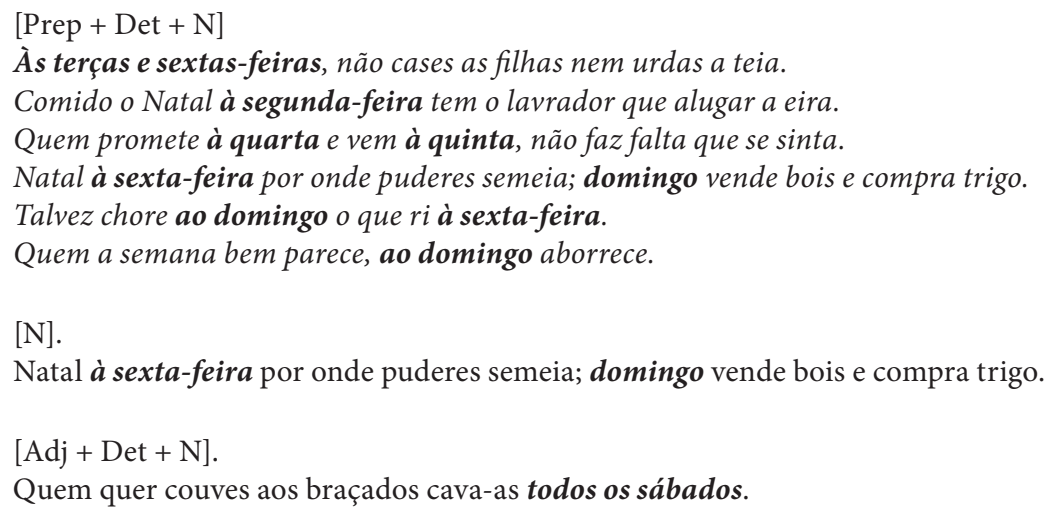

Na função nominal, na função de sujeito ou objeto, o sintagma [N] foi o único encontrado.

Sábados a chover e bêbados a beber, ninguém os pode vencer.

Sexta-feira treze dá azar.

Sábado de Aleluia, carne no prato, farinha na ceia.

Não há domingo sem missa, nem segunda sem premissa.

Não há sábado sem sol, nem domingo sem missa, nem segunda sem preguiça.

\section{0 papel do artigo nos sintagmas preposicionados}

\subsection{Nomes dos dias da semana no singular}

É de notar que no âmbito da nossa análise, a tipologia aspetual e temporal mostrouse ser o fator decisivo apenas nas construções adverbiais representadas pelos sintagmas preposicionais cujo núcleo foi "em" ou "a". Não obstante, esta mesma influência foi verificada no núcleo preposicional $d e$ na função atributiva que, para já, exemplificamos com os seguintes aforismos e provérbios em que aparece a construção de [Prep $+\mathrm{N}]$ :

Ter cara de sexta-feira Santa.

Chuva/Obra de sábado nunca acaba.

Repare-se que no sintagma preposicionado o artigo foi omitido. Assim, a preposição "de", sem o artigo, não só aponta para um carácter gnómico de toda a frase, como também classifica o nome do dia como entidade universal. A presença do artigo, em casos contextualmente compatíveis, permitiria transformar o nome classificador no identificador (Neves, 2000: 394). No caso dos nomes dos dias da semana, não obstante, esta transformação não é possível ou é pouco habitual: 
Classificador $[$ Prep $+\mathrm{N}]$

preocupações de mãe

orçamento de Estado

reunião de sexta-feira

chuva de sábado nunca acaba
Identificador $[$ Prep + Det $+\mathrm{N}]$

preocupações da mãe

orçamento do Estado

reunião da sexta-feira

chuva ${ }^{\star}$ do sábado nunca acabava

A observação minuciosa levou-nos a dividir o sintagma preposicionado, nestes casos, em dois tipos, de acordo com a função sintática e do aspeto. Na função sintática atributiva, a ausência do artigo, inclusive nos casos em que figura o modificador, é canónica quando a expressão remete para a ocorrência singular de ação. Por outro lado, o artigo é indispensável nos sintagmas que implicam a natureza iterativa, frequentativa ou habitual de ação.

reunião de sexta-feira / reunião de sexta-feira passada reuinões das sextas-feiras singularidade

pluralidade

Por outro lado, na função adverbial, a ocorrência do artigo, opostamente às construções atributivas tipo reunião de sexta-feira passada, vê-se submetida à restrição combinatória que consiste na ocorrência do artigo sempre que os nomes do dia da semana são acompanhados por algum modificador. Neste caso, o artigo pode desempenhar a função textual referencial no sentido catafórico. Compare-se as seguintes construções.

depois do sábado de Aleluia // depois da sexta-feira sangrenta.

Artigo remete progressivamente ao modificador de Aleluia ou sangrenta

Assim, verificou-se a ocorrência de quatro diferentes construções sintagmáticas com o determinante ausente ou presente de acordo com a presença ou ausência do modificador e com a função do sintagma:

$$
\begin{aligned}
& \mathrm{N}=[\mathrm{N}+\text { Sprep }=\text { Prep }+\mathrm{N}] \\
& \text { reunião } \boldsymbol{d} \boldsymbol{e} \text { sexta-feira } \\
& \mathrm{SN}=[\mathrm{N}+\text { Sprep }=\text { Prep }+\mathrm{N}+\mathrm{Adj}] \\
& \text { reunião } \boldsymbol{d} \boldsymbol{e} \text { sexta-feira passada } \\
& \mathrm{SPrep}=[\text { Prep }+ \text { Prep }+\mathrm{N}] \\
& \text { depois }{ }^{35} \text { de } \text { sexta-feira. } \\
& \text { SPrep }=[\text { Prep }+ \text { Prep }+ \text { Det }+\mathrm{N}+\text { Adj }] \\
& \text { depois } \text { da } \text { sexta-feira passada }
\end{aligned}
$$

35 Apesar de depois ser considerado advérbio em português, incluimos as construções depois de nos sintagmas preposicionados, sendo que pertencem às locuções chamadas, tradicionalmente, prepositivas (Cunha, Cintra:1999: 552). 
Recorde-se que as construções preposicionadas sem o artigo não vão de encontro a outras construções análogas, onde o nome não se refere aos dias da semana. Assim, contrariamente ao que seria de supor, em outros sintagmas preposicionados ocorre habitualmente o artigo, por exemplo: depois $\boldsymbol{d} \boldsymbol{a}$ revolução, depois $\boldsymbol{d o}$ derrube, depois do aviso, depois $\boldsymbol{d a}$ luta, etc.

Para podermos definitivamente tirar conclusões relativas ao uso do artigo com os nomes dos dias da semana, percorremos nos corpora www.linguateca.pt todas as possíveis ocorrências preposicionadas sem e com o artigo e chegámos às seguintes frequências, todas explicadas abaixo no quadro ilustrativo ${ }^{36}$ :

\begin{tabular}{|l|r|r|r|r|r|r|r|}
\hline \multicolumn{7}{|c|}{$\mathrm{SP}=[$ Prep + Det + N $]$} \\
\hline na/no & $\mathbf{5 4 0 3}$ & $\mathbf{4 4 6 2}$ & $\mathbf{4 6 8 9}$ & $\mathbf{4 4 5 8}$ & $\mathbf{5 4 5 5}$ & $\mathbf{5 3 3 0}$ & $\mathbf{5 3 1 6}$ \\
\hline para a/o & 12 & 8 & 6 & 4 & 7 & 15 & 9 \\
\hline da/do & 22 & 22 & 27 & 27 & 55 & 43 & 149 \\
\hline desde a/o & 2 & 1 & 3 & 1 & 3 & 1 & 6 \\
\hline entre o/a & 1 & 0 & 0 & 0 & 1 & 0 & 0 \\
\hline até o/a & 0 & 0 & 0 & 0 & 0 & 0 & 0 \\
\hline nas/nos & 13 & 0 & 0 & 0 & 0 & 4 & 0 \\
\hline às/aos & $\mathbf{1 4 2}$ & $\mathbf{9 6}$ & $\mathbf{1 4 8}$ & $\mathbf{1 5 4}$ & $\mathbf{1 3 5}$ & $\mathbf{6 2 3}$ & $\mathbf{8 4 0}$ \\
\hline à/ao & $\mathbf{1 6 0}$ & $\mathbf{5 1}$ & $\mathbf{9 7}$ & $\mathbf{7 4}$ & $\mathbf{1 8 9}$ & $\mathbf{3 6 4}$ & $\mathbf{1 0 9 2}$ \\
\hline
\end{tabular}

\begin{tabular}{|l|r|r|r|r|r|r|c|}
\hline \multicolumn{7}{|c|}{$\mathrm{Sp}=[$ Prep. $+\mathrm{N}]$} \\
\hline & segunda & terça & quarta & quinta & sexta & sábado & domingo \\
\hline em & 0 & 0 & 0 & 3 & 3 & 2 & 5 \\
\hline para & 372 & 317 & 307 & 334 & 354 & 451 & 417 \\
\hline de & 2762 & 2416 & 2586 & 2464 & 3132 & 3762 & 4258 \\
\hline desde & 406 & 224 & 248 & 301 & 337 & 270 & 234 \\
\hline entre & 9 & 8 & 17 & 39 & 50 & 30 & 21 \\
\hline até & 281 & 176 & 238 & 276 & 445 & 422 & 771 \\
\hline $\mathrm{N}(\mathrm{pl})$ & 144 & 144 & 187 & 240 & 369 & 352 & 618 \\
\hline
\end{tabular}

Como vemos, procurámos todas as formas possíveis dos dias da semana, relevantes para o nosso estudo sendo que excluímos, nesta parte da pesquisa, a forma plural dos nomes dos dias da semana cujo número com estas preposições se revelou muito baixo. Como se vê nos quadros anteriores, dividimos as construções encontradas de acordo com a ocorrência ou não do artigo definido. Ao mesmo tempo analisámos todas as ocorrências que nos pareciam contraditórias, o que foi verificado em várias situações. Os dados permitiram-nos tirar as seguintes conclusões:

36 A pesquisa em todos os corpora foi realizada em Junho 2013. 
1. do primeiro quadro, que analisou a presença do artigo nos sintagmas preposicionados, é deduzível que os números mais elevados da ocorrência do artigo se referem às preposições "em" e “a”;

2. do segundo quadro, que analisou a omissão do artigo, deduz-se que as ocorrências mais frequentes do artigo omitido se referem aos núcleos preposicionais (para, de, desde, entre, sem);

3. não obstante, como já adiantámos, também encontrámos casos contraditórios de imprevisibilidade, que foram registados apenas nos sintagmas adverbiais sempre que o dia da semana era seguido por um modificador: "depois do sábado de Aleluia, depois da quinta-feira negra, antes da sexta-feira sangrenta, para a sexta-feira, 17 de junho" e também na locução prepositiva: "por causa de" (por causa da segunda-feira);

4. a seguir, verificou-se uma curiosidade relativa à ocorrência de "em" sem artigo, com os nomes dos dias da semana litúrgica. Devido ao número reduzido de frases encontradas, não podemos tirar nenhumas conclusões definitivas. Ao consultarmos esta construção com os falantes nativos, parece que podemos atribuir estas formas à linguagem escrita, enquanto na linguagem falada, os nomes dos dias da semana se usam com o artigo.

\subsection{Nomes dos dias da semana em plural}

É de salientar que o artigo com os nomes dos dias da semana no plural, é mais frequente, comparativamente ao caso anterior. Embora estas construções não sejam abundantes, por mais curioso que pareça, quando usadas com as preposições "para" ou "de", aparecem sempre com o artigo:

\begin{tabular}{|l|c|c|c|c|c|c|c|}
\hline & segundas & terças & quartas & quintas & sextas & sábados & domingos \\
\hline $\begin{array}{l}\text { em/nas } \\
\text { (nos) }\end{array}$ & $0 / \mathbf{1 4}$ & $0 / 2$ & $0 / 3$ & $2 / 2$ & $2 / 16$ & $2 / 60$ & $5 / 61$ \\
\hline $\begin{array}{l}\text { para/para } \\
\text { as (os) }\end{array}$ & $0 / 8$ & $0 / 14$ & $0 / 5$ & $0 / 7$ & $1 / 9$ & $0 / 13$ & $3 / 13$ \\
\hline $\begin{array}{l}\text { de/das } \\
\text { (dos) }\end{array}$ & $0 / 46$ & $0 / 36$ & $0 / 78$ & $0 / 89$ & $1 / 73$ & $9 / 66$ & $11 / 90$ \\
\hline
\end{tabular}

Ora, como vemos, o número destes sintagmas preposicionados mostra-se muito baixo para podermos tirar conclusões fidedignas devido à pouca probabilidade de estas referências temporais serem regulares e apontarem para uma iteratividade/frequência/ gnomia/hábito relacionados com um certo dia. Mas de acordo com a tipologia aspetual, a dicotomia singularidade $\times$ pluralidade reflete-se na escolha de um ou doutro sintagma. Com base nesta dicotomia aspetual, podemos colocar de novo em oposição duas formas: de sexta-feira e das sextas-feiras. Logicamente, o sentido de "das sextas-feiras" é dado pela forma plural que reflete a pluralidade do evento/ação ou estado. Assim chegou-se a dividir duas construções em $[$ Prep + Det + N] e $[$ Prep + N]. Compare-se as seguintes frases: 
Aspeto pontual (ocorrência singular)

Os dez bancos credores do conjunto de empresas Copaz / Iberol não chegaram a acordo, na sua reunião de sexta-feira passada, sobre a forma de solucionar a presente situação, a braços com um passivo financeiro acumulado de aproximadamente 24 milhões de contos. ${ }^{37}$

Aspeto durativo (ocorrência plural):

O Conselho de Ministros espanhol tem de decidir hoje, na sua habitual reunião das sextas-feiras, sobre um espinhoso assunto: a seca que aflige algumas zonas do país obriga à transferência, com sinal de urgência, de recursos hídricos, da represa do Tejo de Entrepeñas para a bacia do rio Segura. ${ }^{38}$

\section{Conclusão}

Como vimos, ao longo do nosso trabalho surgiram diferentes questões que nos levaram a sistematizar todas as construções com os nomes dos dias da semana, os quais tentámos encaixar em diferentes "gavetas" sintáticas e semânticas.

A variabilidade estutural dos sintagmas preposicionados ou não preposicionados que contêm um nome do dia da semana constitui um problema que pode ser analisado, subatomicamente, sob vários pontos. Um primeiro fator que se mostrou relevante foi o da referência temporal que apresentou cinco pontos distribuídos no eixo temporal. Vimos que a seleção da estrutura interna dos sintagmas analisados se depreende, muitas vezes, da perceção subjetiva e individual do interlocutor. Ao mesmo tempo, um dos pontos problemáticos da nossa análise foi o da flutuação dos modificadores próximo e passado, que mostraram uma considerável assimetria nos sintagmas preposicionados e não preposicionados: isto é, ambos são, preferencialmente, colocados em posição pré-nominal no sintagma preposicionado, mas, por outro lado, em sintagmas não preposicionados, tendem para a posição pós-nominal. Para cada um dos pontos no eixo temporal foram encontradas construções prototípicas, as quais, como verificámos, podem ser usadas em todos os subtipos aspetuais (eventos, processos, culminações, processos culminados, pontos) e classes aspetuais (valores incoativo, causativo, incetivo, permansivo, cessativo e conclusivo, cursivo e permansivo). Já no que diz respeito à subdivisão do valor durativo, foi verificada a relevância da singularidade ou pluralidade da proposição. Encontrámos casos onde as expressões adverbiais estudadas apresentaram um carácter gnómico e universal, o que também se refletiu na análise das construções preposicionadas em função modificadora. Como último ponto da pesquisa foi analisada a ocorrência do artigo nos sintagmas preposicionados em que, como vimos, a variabilidade da ocorrência se depreende diretamente do núcleo preposicional.

37 Costa, Santos \& Cardoso (2008), http://linguateca.pt/CETEMPublico.

38 Idem. 


\section{REFERÊNCIAS BIBLIOGRÁFICAS}

Bechara, E. (1999): Moderna Gramática Portuguesa. Rio de Janeiro: Lucerna.

Brito A. M. - Oliveira, F. (1997): Nominalization, Aspect and Argument Structure. In: G. Matos I. Miguel - I. Duarte - I. Faria (eds.), Interfaces in Linguistic Theory. Lisbon: A.P.L./Colibri, pp. $57-80$.

Buda, J. (2013): Sobre a Colocação do Adjetivo no Sintagma Nominal. Tese de mestrado. 2013. Brno: Universidade de Masaryk.

Cunha, C. - Cintra, L. F. (1999): Nova Gramática do Português Contemporâneo. Lisboa: João Sá da Costa.

Castilho, A. T. de (1966): Introdução ao estudo do aspecto verbal na língua portuguesa. Marília: FFCL.

Castilho, A. T. de (2010): Nova Gramática do Português Brasileiro. São Paulo: Contexto.

Cuesta.V. P. - Da Luz, M. A. M. (1980): Gramática da Língua Portuguesa. Lisboa: Edições 70.

Hampl, Z. (1972): Stručná mluvnice portugalštiny. Praha: Academia.

Hricsina, J. (2013): A Posição do Adjetivo no Sintagma Nominal no Português Contemporâneo: Análise Corporal. Acta Universitatis Carolinae Philologica. Romanistica Pragensia, vol. 19, núm. 2, pp. 203-218.

Jindrová, J. (2011): Modotemporální a aspektuální význam portugalského složeného perfekta. Studie z korpusové lingvistiky. Korpusová lingvistika: Praha, vol. 14, núm. 1, pp. 219-230.

Lapa, M. R. (1984): Estilística da Língua Portuguesa. Coimbra: Editora Limitada.

Lopes, Ó. (1991): Gramática simbólica do Português. Lisboa: Instituto Gulbenkian de Ciência.

Madeira, A. (2008): Aquisição de L2. In: P. Osório - R. Meyer (eds.), Português Língua Segunda e Língua Estrangeira. Lisboa: Lidel, Edições Técnicas, pp.189-203.

Mateus, M. H. M. - Brito, A. M. - Duarte, I. - Faria I. et al. (1989): Gramática da Língua Portuguesa. Lisboa: Editorial Caminho - Colecção Universitária.

Mateus, M. H. M. - Brito, A. M. - Duarte, I. - Faria I. et al. (2003): Gramática da Língua Portuguesa. Lisboa: Editorial Caminho - Colecção Universitária.

Oliveira, F. - Lopes, A. (1995): Tense and Aspect in Portuguese. In: Thieroff, R. (org.), Tense Systems in European Languages, vol. 2, Max Niemeyer Verlag: Tubingen, pp. 95-115.

Parsons, T. (1990): Events in Semantics of English. A Study in Subatomic Semanitcs. Cambridge, Mass: The MITT Press.

Santos, D. (2008): Corporizando algumas questões. In: Tagnin, S. E. O. - Araújo Vale, O. (eds.), Avanços da Lingüística de Corpus no Brasil. São Paulo: Editora Humanitas, pp. 41-66.

Svobodová, I. (2010): Stylisticko-pragmatické faktory použití členu v současné portugalštině. Brno: Muni press.

Svobodová, I. (2009): Tempo e espaço como fatores linguísticos e extralinguísticos que compõem o semema do artigo. Études Romanes de Brno, vol. 30, núm. 1, pp. 121-139.

Tláskal, J. (1984): Observações sobre Tempos e Modos em Português. Estudos de Linguística Portuguesa. Coimbra: Coimbra Editora, pp. 237-255.

Zavadil, B. - Čermák, P. (2010): Mluvnice současné španělštiny, Lingvisticky interpretační prístup. Praha: Karolinum.

\section{Dicionários consultados}

Jindrová, J. - Pasienka, A. (2007): Portugalsko-českýslovník. Praha: Leda.

Jindrová, J. - Hamplová, S. (1997): Česko-portugalský slovník. Praha: Leda.

Hampl, Z. (1975): Portugalsko-český slovník. Praha: SPN.

Houaiss, A. - de Salles Villar, M. (2002): Dicionário Houaiss da Língua Portuguesa. Lisboa: Círculo de Leitores.

Novo Dicionário Aurélio versão 5.0 - Dicionário Eletrônico [CD-ROM]. Positivo Informática: (2004).

Buarque de Holanda Ferreira, A. (1999): Novo Aurélio Século XXI: O Dicionário da Língua Portuguesa. Rio de Janeiro: Nova Fronteira: (1999).

Dicionário da Língua Portuguesa Contemporânea (2001). Academia das Ciências de Lisboa. 
Dicionários consultados online

http://aulete.uol.com.br

www.priberam.pt

www.aurelio.pt

\section{Corpora consultados online}

www.linguateca.pt

www.corpusdoportugues.pt

www.korpus.cz (Český národní korpus - InterCorp. Ústav Českého národního korpusu FF UK,

Praha)

\section{Iva Svobodová}

Departamento de Línguas e Literaturas Românicas da Universidade de Masaryk

Arna Nováka 1, 60200 Brno

9255@mail.muni.cz 